THE COMPOSITION OF THE TUBERCULOSIS, ETC. 605

The method, of course, depends upon the fact that it is impossible to throw down the glucinum until the greater part of the acid has been saturated, the glucinum remaining in solution as basic sulphate. Iron and aluminum, on the contrary, are easily separated. Some care is needed in order to get rid of the last trace of iron, which persistently remains in solution until the point at which the precipitation of glucinum begins is almost reached.

A sample prepared in this way was perfectly soluble in hydrochloric acid, gave no reaction for iron with potassium ferrocyanide, was completely soluble in an excess of ammonium carbonate and caustic potash. The ammonium carbonate solution gave no precipitate on the addition of ammonium oxalate. The nethod is exceedingly simple, convenient and cheap, and leaves nothing to be desired.

\title{
THE COMPOSITION OF THE TUBERCULOSIS AND GLANDERS BACILLI,
}

By E. A. DE Schweinitz and Marion Dorset, Received April $30,1895$.

W HILE many examinations of the products of bacilli have been made during the past years comparatively little attention has been paid to a comparison of the proximate and ultimate analyses of the germs themselves that are morphologically different, and produce different pathological changes.

Cramer ${ }^{1}$ gives the results and analyses of cholera germs from different sources, and concludes that upon easily assimilable media the composition of the bodies of the same germ from different sources, and which vary in virulence, is about the same. Where, however, the media supply food that is but difficultly assimilable the composition of the bodies of the germs will vary. The comparison which he makes between these and several. other species shows a variation which indicates a distinct and characteristic composition for each germ.

We have had occasion to collect large quantities of the tuberculosis and glanders bacilli, and have submitted the germs, grown both on the ordinary glycerol beef broth and on artificial

1 Arch.f. Hygiene, 16. 
nıedia, to proximate and ultimate analyses. The results are presented in tabulated form.

The germs were freed by filtration from the culture liquid and the last traces of the soluble products removed by washing either with water alone or with the addition of sodiun carbonate. The germs were then dried over sulphuric acid and, just before analysis, were further dried at $100^{\circ} \mathrm{C}$. In drying, the germs uncierwent but slight change of color if they had been thoroughly washed. The analyses were made with the germs obtained from one and the same original culture, but the growths of eight or ten different generations were mixed together to secure an arerage sample. The artificial media used for the cultivation of the tuberculosis bacillus had the following composition:

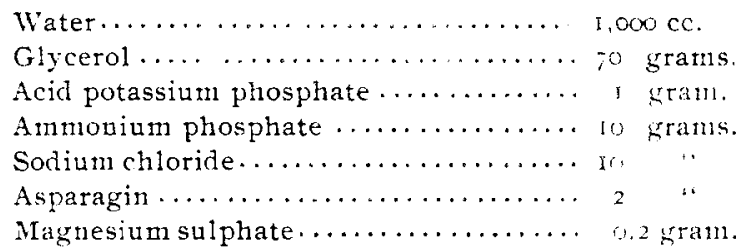

In table I are given the deterninations of the carbon, hydrogen, nitrogen, phosphorus, sulphur, ash, in column I, calculated upon the weight of the sample dried at $100^{\circ} \mathrm{C}$.; in column II, upon the ash free substance. With the exception of the nitrogen there seems to be but little variation in the composition of the germs grown on beef broth or on artificial culture media.

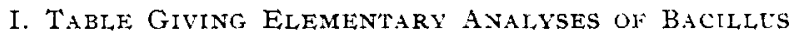
TUBERCULOSIS.

\begin{tabular}{|c|c|c|c|c|c|c|c|c|}
\hline & \multicolumn{2}{|c|}{ Beef broth. } & \multicolumn{2}{|c|}{ Beef broth. } & \multicolumn{2}{|c|}{ Beef broth. } & \multicolumn{2}{|c|}{ Artificial media } \\
\hline & \multicolumn{2}{|c|}{ Per cent. } & \multicolumn{2}{|c|}{ Per cent. } & \multicolumn{2}{|c|}{ Per cent. } & \multicolumn{2}{|c|}{ Pet cent. } \\
\hline & 1. & II. & I. & II. & I. & II. & I. & II. \\
\hline 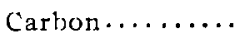 & $\ldots$ & $\ldots$ & 60.12 & 62.61 & 62.98 & 64.06 & 62.16 & 63.35 \\
\hline Hydrogen....... & 9.22 & 9.60 & $9 \cdot 15$ & $9 \cdot 53$ & $7 \cdot 39$ & $7 \cdot 52$ & 9.19 & 9.36 \\
\hline Nitrogen........ & $7 \cdot 34$ & 7.64 & 7.27 & 7.40 & 8.04 & 8.18 & 8.94 & 9.14 \\
\hline Sulphur ....... & 0.44 & 0.45 & $\cdots$ & $\cdots$ & $\cdots$ & $\ldots$ & 0.22 & 0.23 \\
\hline $\left.\begin{array}{r}\text { Phosphorus sol- } \\
\text { uble in dilute } \\
\text { nitric acid... }\end{array}\right\}$ & 0.66 & & 0.19 & $\cdots$ & $\cdots$ & $\cdots$ & $\cdots$ & $\cdots$ \\
\hline $\begin{array}{c}\text { Phosphorus, to- } \\
\operatorname{tal} \text { (Carius)... }\end{array}$ & 0.77 & & 0.83 & & 0.87 & $\cdots$ & 0.66 & \\
\hline Ash ............ & 4.03 & $\ldots$ & 4.03 & $\cdots$ & 1.77 & $\cdots$ & 1.92 & $\cdots$ \\
\hline
\end{tabular}


THE COMPOSITION OF THE TUBERCULOSIS, ETC.

Table II gives the elementary analyses of the bacillus of glanders. The germs for these analyses were filtered off, washed a number of times with water and cold absolute alcohol and dried.

A comparison of these results with those of the bacillus of tuberculosis shows a great and distinctive variation.

II. Table Giving Elementary Analyses of Bacillus Maliei.

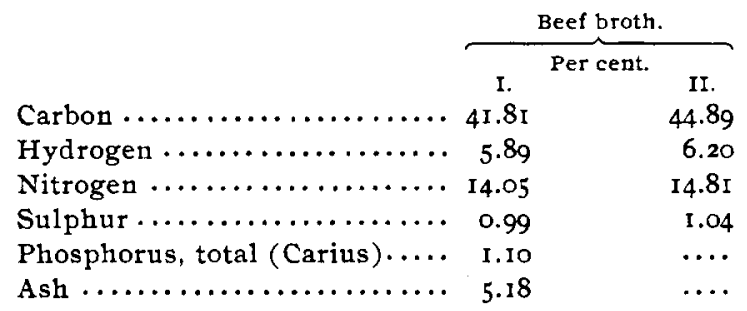

The variations in the composition of these two bacilli is still more apparent in a comparison of the amount of the proximate constituents as shown in tables III, IV, V, and VI. The determinations were made according to the general methods prescribed for such analyses. The nitrogen determinations were made by the Kjeldahl method, and from these results the albuminoids were calculated. The figures reported in the table as cellulose were obtained by treating the residue from the alcohol extract with I.25 per cent. caustic soda for forty to sixty minutes, washing well, then digesting the residue with 1.25 per cent. sulphuric acid for the same length of time, washing, and drying. The loss by ignition of the dried residue should indi. cate cellulose.

The presence of cellulose in the organs of tuberculous individuals has been examined by Freund, Dreyfuss, Toyosaku Nishimura, with somewhat discordant results. Freund ( Jahr. d. g. Wiener Aerzte, 28, I886) treated the organs and blood from twenty-five different cases, first by extracting with ether and alcohol, then with dilute sulphuric acid. In this way there were left behind hard round lumps about the size of tubercles, which, while insoluble in dilute were soluble in strong sulphuric acid. This solution diluted with water and heated gave the reduction test for sugar. 
III. Bacirlus Tuberculosis. Beef Broth $\%$.

\begin{tabular}{|c|c|c|c|c|c|c|}
\hline & \multicolumn{2}{|c|}{ i. } & \multicolumn{2}{|c|}{2.} & \multicolumn{2}{|c|}{ Average. } \\
\hline & \multicolumn{2}{|c|}{ Per cent. } & \multicolumn{2}{|c|}{ Per cent. } & \multicolumn{2}{|c|}{ Per cent. } \\
\hline & I. & II. & I. & II & I. & II. \\
\hline Ether extract....... & 39.64 & 41.29 & 38.95 & 40.32 & 39.29 & 40.80 \\
\hline Alcohol extract ..... & $\ldots$ & $\ldots$ & $\ldots$ & $\ldots$ & $\ldots$ & $\ldots$ \\
\hline Albuminoids........ & $45.8 \mathrm{I}$ & $47 \cdot 31$ & 45.87 & 47.85 & 45.84 & $47 \cdot 53$ \\
\hline Cellulose .......... & 6.95 & 7.24 & $\ldots$ & $\ldots$ & 6.95 & 7.24 \\
\hline Ash $\ldots . . . \ldots \ldots \ldots$ & 4.12 & $\ldots$ & 3.94 & $\cdots$ & 4.03 & $\cdots$ \\
\hline
\end{tabular}

IV. Bacillus Tubkrculosis. Beef Broth 2.

\begin{tabular}{|c|c|c|c|c|c|c|}
\hline & \multicolumn{2}{|c|}{ I. } & \multicolumn{2}{|c|}{2.} & \multicolumn{2}{|c|}{ Average. } \\
\hline & \multicolumn{2}{|c|}{ Percent. } & \multicolumn{2}{|c|}{ Per cent. } & \multicolumn{2}{|c|}{ Per cent. } \\
\hline & I. & II. & I. & II. & I.. & II. \\
\hline Ether extract ....... & $\cdots$ & $\cdots$ & $\ldots$ & $\cdots$ & $\cdots$ & $\ldots$ \\
\hline Alcohiol extract... . & 3.04 & 3.10 & $\cdots$ & $\cdots$ & 3.04 & 3.10 \\
\hline Albuminoids....... & 50.25 & 51.12 & $45 \cdot 43$ & 46.25 & 47.84 & 48.68 \\
\hline Cellulose...$\ldots \ldots$ & $7 \cdot 37$ & 7.68 & $\ldots$ & $\ldots$ & $7 \cdot 37$ & 7.68 \\
\hline 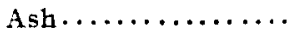 & 1.67 & $\ldots$ & I. 87 & $\ldots$ & I. 77 & $\ldots$ \\
\hline
\end{tabular}

V. Bacilitus Tuberculosis. Artificial Media.

\begin{tabular}{|c|c|c|c|c|c|c|}
\hline & \multicolumn{2}{|c|}{ r. } & \multicolumn{2}{|c|}{2.} & \multicolumn{2}{|c|}{ Average. } \\
\hline & \multicolumn{2}{|c|}{ Per cent. } & \multicolumn{2}{|c|}{ Per cent. } & \multicolumn{2}{|c|}{ Per ceut. } \\
\hline & I & II. & I. & II. & I. & II. \\
\hline Ether extract...... & $37 \cdot 76$ & 37.88 & 37.98 & $3^{8.71}$ & $37 \cdot 57$ & $3^{8.34}$ \\
\hline Alcohol extract..... & 4.69 & 4.79 & 4.19 & 4.28 & 4.44 & 4.53 \\
\hline Albuminoids........ & 55.87 & 57.12 & $\cdots$ & $\ldots$ & 55.87 & 57.12 \\
\hline Cellulose .......... & 3.82 & 3.89 & 5.69 & 5.80 & 4.75 & 4.84 \\
\hline Ash $\ldots \ldots \ldots \ldots \ldots$ & 1.92 & $\ldots$ & $\ldots$ & $\ldots$ & 1.92 & $\ldots$ \\
\hline
\end{tabular}

VI. Baciri,us MaLiei. Beff Broth.

\begin{tabular}{|c|c|c|c|c|c|c|}
\hline & \multicolumn{2}{|c|}{ I. } & \multicolumn{2}{|c|}{2.} & \multicolumn{2}{|c|}{ Average. } \\
\hline & \multicolumn{2}{|c|}{ Per cent. } & \multicolumn{2}{|c|}{ Per cent. } & \multicolumn{2}{|c|}{ Per cent. } \\
\hline & I. & II. & I. & II. & I. & II. \\
\hline Ether extract...... & 7.91 & 8.26 & 7.67 & 8.09 & $7 \cdot 78$ & 8.I 7 \\
\hline Alcohol extract.... & $\ldots$ & $\ldots$ & $\cdots$ & $\ldots$ & $\ldots$ & $\cdots$ \\
\hline Albuminoids........ & 89.81 & 94.68 & $85.7 \mathrm{I}$ & 90.43 & 87.76 & 92.55 \\
\hline Cellulose .......... & 5.87 & 6.19 & $\ldots$ & $\ldots$ & 5.87 & 6.19 \\
\hline Ash $\ldots \ldots \ldots \ldots \ldots$ & 5.18 & $\ldots$ & $\ldots$ & $\cdots$ & $5 \cdot 18$ & $\cdots$ \\
\hline
\end{tabular}

Schulze's method was also used. Lungs, spleen, peritoneum, and dried blood were cut up finely and subjected to the action of nitric acid and potassium chlorate, white, round nodules, or a flocculent substance were left behind, which, submitted to analysis, after solution in cupric ammonia and reprecipitation, gave results corresponding to cellulose. 
Nishimura' used for experiment the lungs and blood of tuberculous cows and also of men. The organs, after being finely divided were extracted with ether and alcohol and then with two per cent. sulphuric acid.

The residue, when treated with strong sulphuric acid, gave a solution that yielded the Trommer sugar test only twice out of six experiments.

Nishimura then tried the alkali method. The material was fused with potassium hydrate in the oil-bath at $180^{\circ} \mathrm{C}$, the fusion acidified with sulphuric acid, then made sliglitly alkaline and allowed to stand until clear. The residue was filtered off and tested for cellulose. By this method, from the lungs of a grown person a slight reaction for cellulose resulted with Trommer's test. The spleen and liver, treated in the same way also indicated cellulose. In two cases from children, lungs, liver, and spleen gave the cellulose test.

How should this cellulose content be present in the organs? The most plausible supposition is the assumption that this comes from the presence of the bacilli themselves, and that the bodies of the latter are rich in cellulose. Upon this assumption Dreyfuss $^{2}$ examined several varieties of bacilli, bacillus subtilis, pus bacillus, aspergillus glaucus, and by the fusion method with caustic potash, succeeded in obtaining the reduction and phenylhydrazine tests.

Nishimura, found, however, that other bacilli, $c . g$, the water bacillus No. 28, dich not show the presence of cellulose. He extended his researches to the tubercle bacilli themselves. He made four tests upon the tubercle bacilli from glycerol bouillon cultures using the alkali method, but obtained no reduction. From this he concludes that cellulose is not present in the tubercle bacilli.

In our examination of the tubercle bacilli, as indicated above, the digestion of the residue, after extraction with ten per cent. sulphuric acid gave distinct reduction tests with Felhing's solu. tion. In two experiments Hoppe-Seyler's method, by fusing with caustic potash at $\mathrm{I} 80^{\circ}$, was used. In the one a good reduction test was obtained; in the other the reduction test failed.

1 Alch,f. Hygiene, 21, [1], 52.

2 Ztsihr. Physiol. Chem., 18, $[3,4], 367$. 
From these tests we would conclude that cellulose is present in the tubercle bacilli, but in very minute amount, which may, in some instances, escape detection by the methods generally adopted. Nishimura thinks that possibly the tubercle bacilli form cellulose when they grow in the body, but not on artificial culture media. The fact, however, that the analyses indicated cellulose, both when grown upon glycerol beef broth and upon the mineral salt cultures, would make it probable that the cellulose is a normal constituent and can be produced by the germ from whatever maierial it feeds upon.

The proximate analyses of the glanders bacilli show results which are markedly different from those obtained with the tubercle bacilli. While the determination of cellulose by the method of difference would indicate its presence, the fusion with caustic potash, according to the same method adopted for the tubercle germs, and sibsequent treatment with sulphuric acid indicates the absence $\mathrm{f}$ cellulose. Care was taken in filtering the tuberculosis and glandery germs that they were not contaminated with cellulose from filter-paper. The most of them were filtered through porcelain and then scraped off.

In order to show more clearly the variation in the body composition of different germs the following table is appended which gives results obtained by Cramer and others, with different germs, upon varying media. The change in the nitrogen content is very marked, and while the difference of medium infl1ences this to some extent there is still sufficient variation in the different germs to permit of a possible distinction of species. While the products of germs are invaluable as an aid to identification it would appear that the chemical study of the bodies of the germs and the differences in their proximate constituents, especially albuminoids and fat, and a more distinctive study of the albuminoids might be very useful in aiding classification.

In order to form some idea of the composition of the fat extracted from the tuberculosis and glanders bacilli, the fats were saponified with caustic soda and the fatty acid separated. The quantity of acids obtained, however, was small and it was only possible to make melting-point determinations. From these the acids of the glanders seemed to be oleic and palmitic, those from the tubercle bacilli, palmitic and arachidic acid. 
The difference in the fatty acids apparent in these two, and which would probably vary as much in other germs, could doubtless be made of use in classification. This study is being continued further and extended to the hog cholera, swine plague, and allied germs. Bacilli.
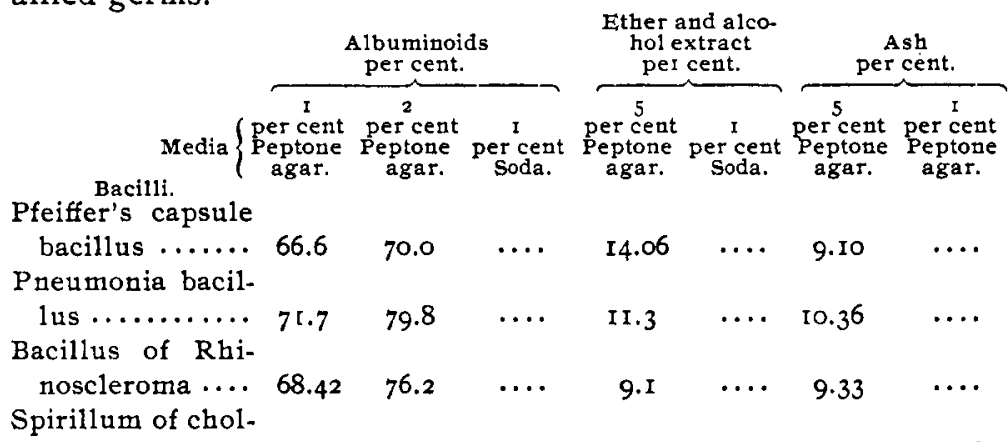

\begin{tabular}{|c|c|c|c|c|c|}
\hline $\begin{array}{l}{ }^{7} \\
\text { per cent } \\
\text { Glycerol } \\
\text { beef } \\
\text { broth. } \\
\text { per cent }\end{array}$ & $\begin{array}{c}7 \\
\text { per cent } \\
\text { Artifi- } \\
\text { cial } \\
\text { media. } \\
\text { per cent }\end{array}$ & $\begin{array}{c}5 \\
\text { per cent } \\
\text { Glycerol } \\
\text { beef } \\
\text { broth. } \\
\text { per cent }\end{array}$ & $\begin{array}{c}\text { I } \\
\text { percent } \\
\text { Peptone } \\
\text { beef } \\
\text { broth. } \\
\text { per cent p }\end{array}$ & $\begin{array}{l}\text { Car. } \\
\text { bon. } \\
\text { er cent }\end{array}$ & $\begin{array}{c}\text { Hydro. } \\
\text { gez. } \\
\text { per ceat }\end{array}$ \\
\hline
\end{tabular}

$\begin{array}{lllllllll}\text { Tuberculosis } \ldots . . & 7.34 & 8.94 & \ldots & \ldots & \ldots & 62.98 & 7.34 & \text { I.77 }\end{array}$

$\begin{array}{lllllllll}\text { Glanders } \ldots . . . . . ~ & \ldots & \ldots & \ldots & 14.05 & \ldots & 4 \mathrm{I} .89 & 5.89 & 5.18\end{array}$

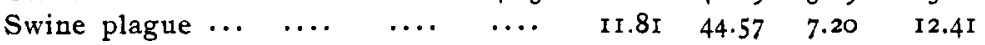

BIOCHEMIC LABORATORY,

BUREAU OF ANIMAL INDUSTRY.

\section{A CONVENIENT FORM OF UNIVERSAL HAND-CLAMP.'}

By PETER, T. AUSTEN AND W. A. HORTON.

Received April 23, 1895.

THE various holders and hand-clamps used for holding testtubes and smaller forms belong, as a rule, to two classes. The bite is effected either by a spring or by a pressure exerted by the hand. The difficulty with the first class of holders is that the spring is often inconveniently strong for delicate tubes, and not strong enough for flasks. The second class often fails when long continued holding is involved, as muscular pressure relaxes after a time.

The following little device was worked out to afford a con-

1 Read before the New York Section, December, 1893 . 